\title{
elyra
}

\section{Espaço aéreo}

\section{Ricardo Tiago Moura}

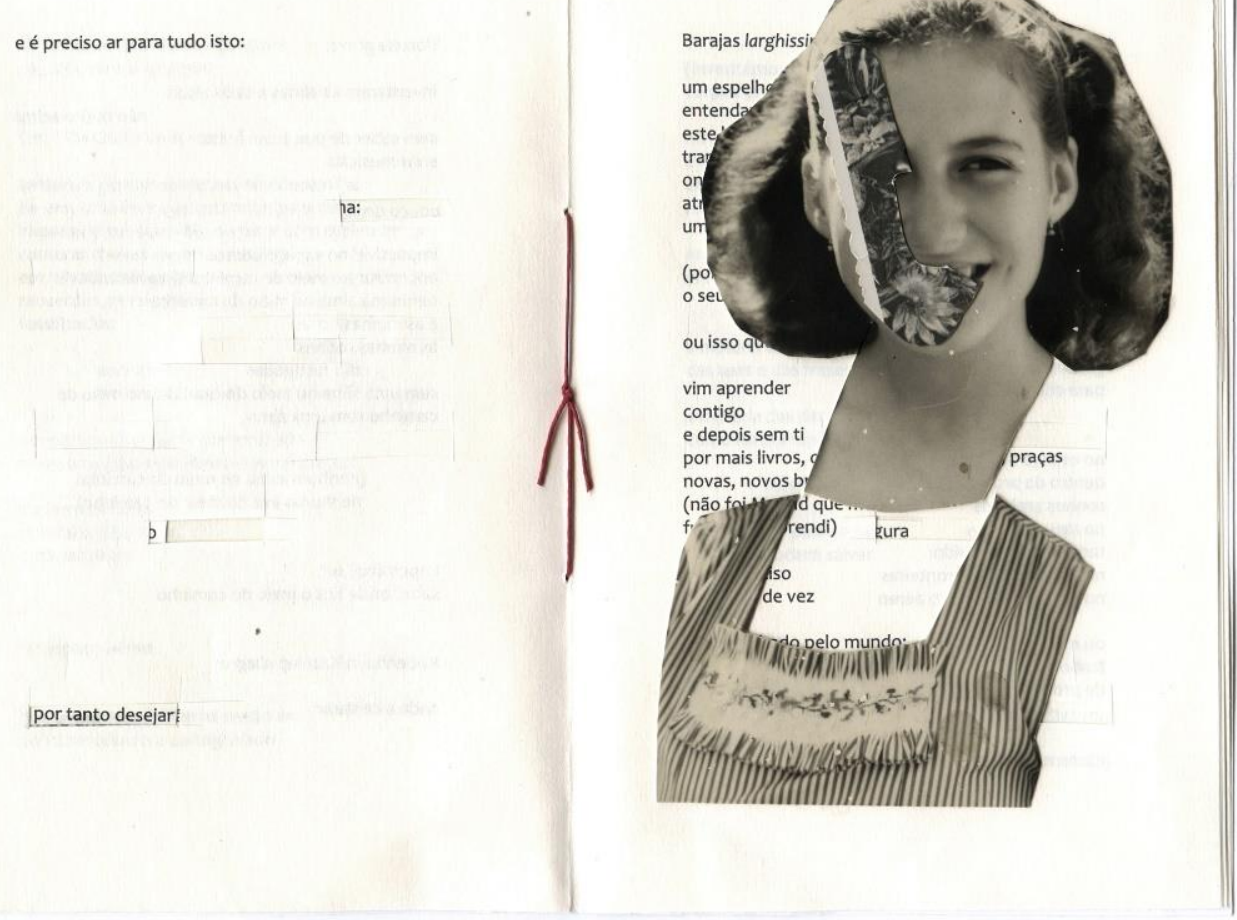




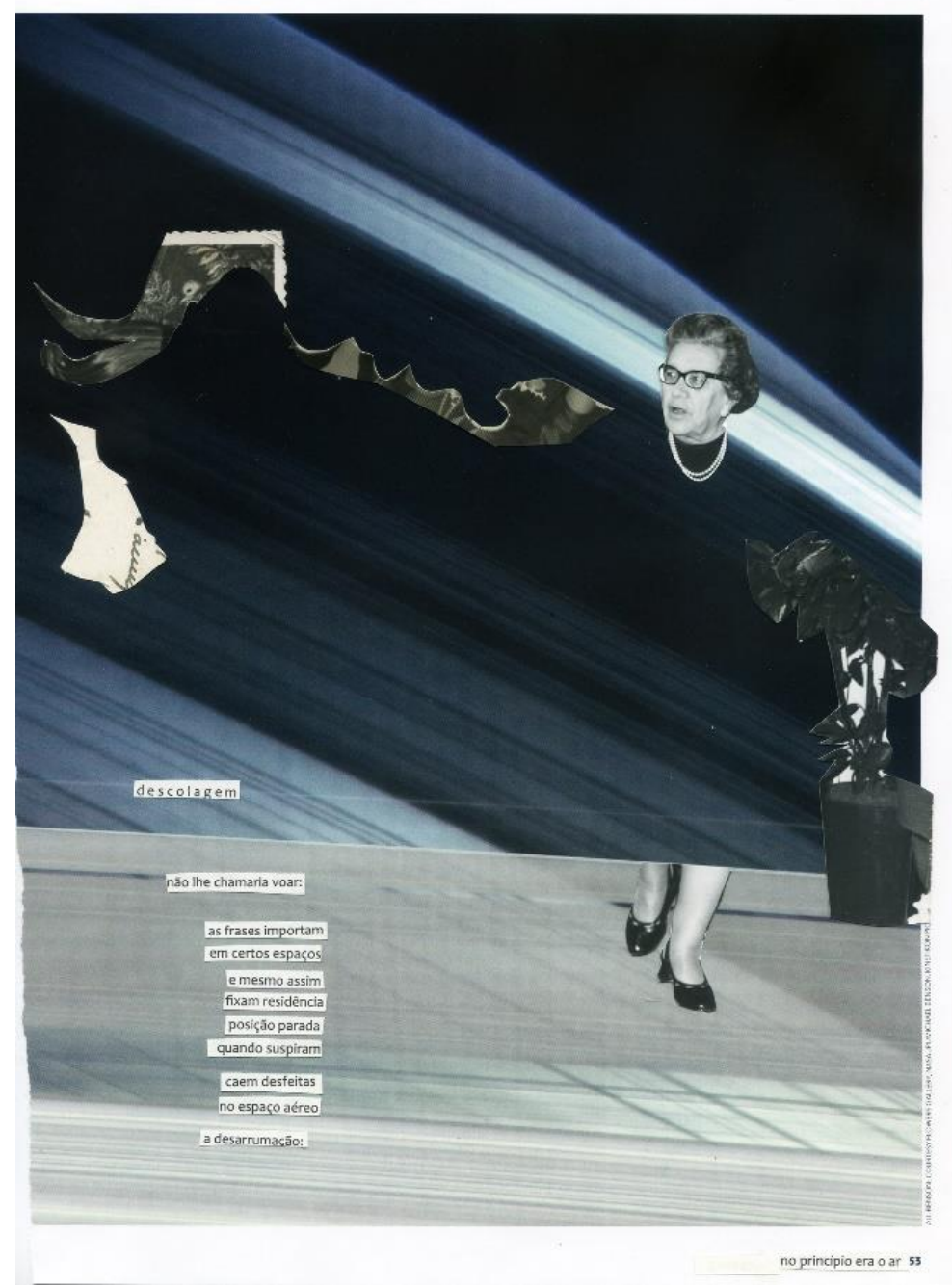




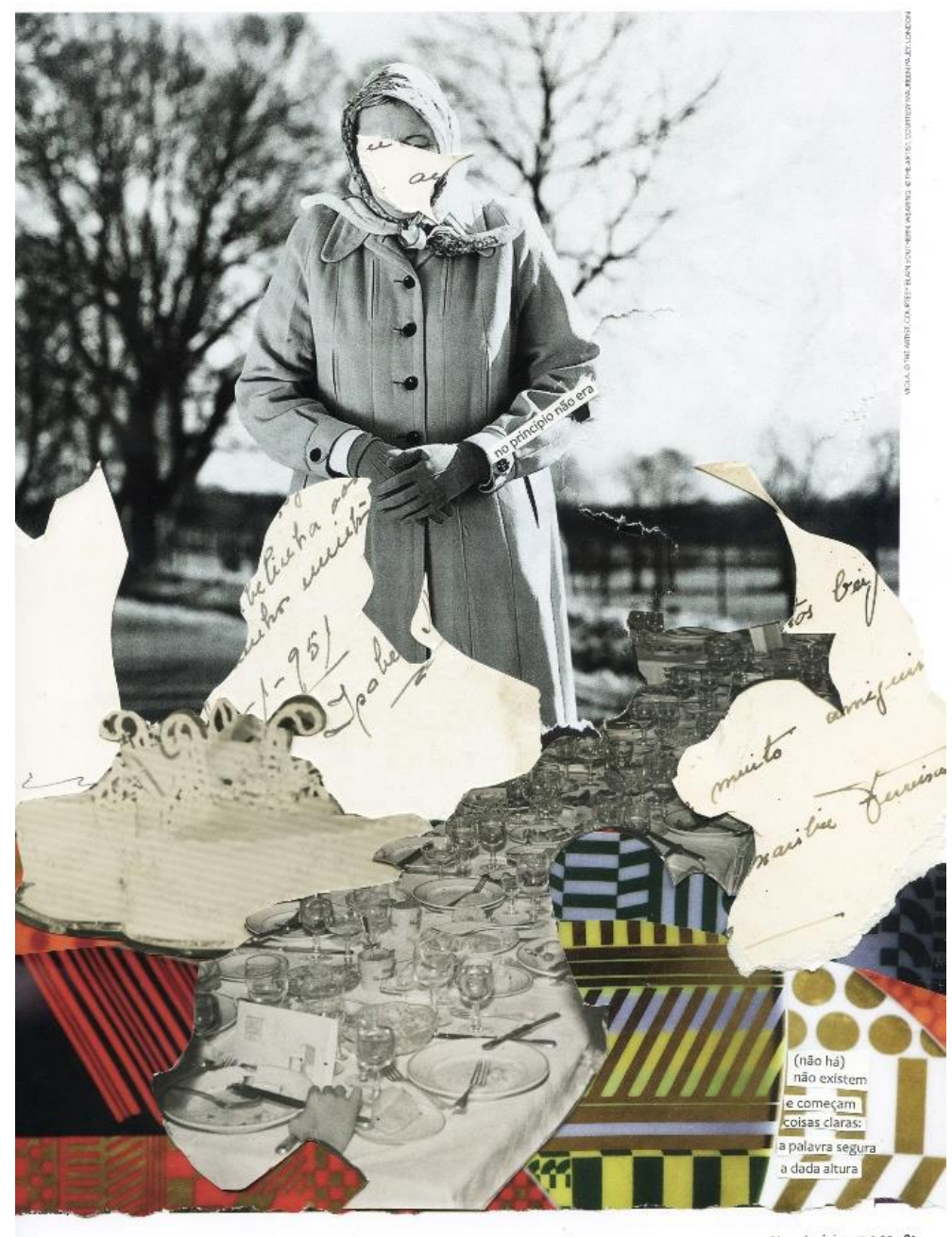




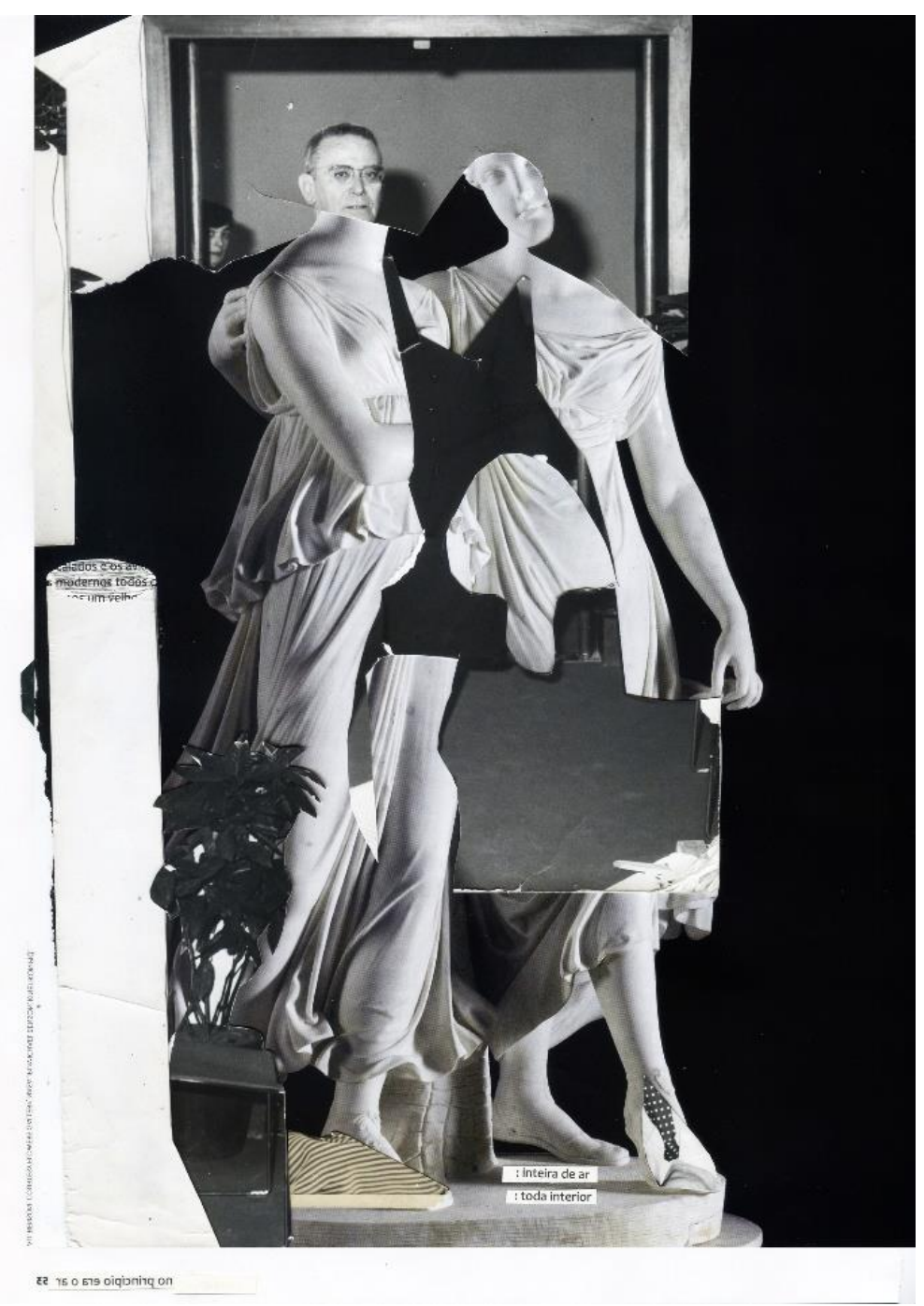

